\title{
Structural Basis for the Interaction of 14-3-3 $\beta$ with Tricarboxylic Acid Cycle Intermediate Malate
}

\author{
Zhiqiang Hou ${ }^{1,2^{*}}$, Lijing Su, ${ }^{1,3}$ Xiaoyan Liu ${ }^{4}$ \\ ${ }^{1}$ Department of Biophysics, Dallas, USA \\ ${ }^{2}$ Center for Alzheimer and Neurodegenerative Disease, Dallas, USA \\ ${ }^{3}$ Center for the Genetics of Host Defense, Dallas, USA \\ ${ }^{4}$ Department of Microbiology, University of Texas Southwestern Medical Center, Dallas, USA \\ Email: *zhiqiang.hou@utsouthwestern.edu
}

How to cite this paper: Hou, Z.Q., Su, L.J. and Liu, X.Y. (2017) Structural Basis for the Interaction of $14-3-3 \beta$ with Tricarboxylic Acid Cycle Intermediate Malate. Journal of Biosciences and Medicines, 5, 36-47. https://doi.org/10.4236/jbm.2017.58003

Received: June 24, 2017

Accepted: July 31, 2017

Published: August 3, 2017

Copyright $\odot 2017$ by authors and Scientific Research Publishing Inc. This work is licensed under the Creative Commons Attribution International License (CC BY 4.0).

http://creativecommons.org/licenses/by/4.0/

\begin{abstract}
The protein family of 14-3-3(s) has risen to a position of higher importance as an adaptor protein in cell biology. The seven highly conserved human 14-3-3 proteins coordinate diverse cellular processes including apoptosis, DNA damage response, protein trafficking, and others. In liver hepatocytes, 14-3-3 $\beta$ binds to Ser ${ }^{196}$-phosphorilated glucose-responsive carbohydrate response element-binding protein (ChREBP) to inhibit converting excess carbohydrate to fat by regulating the nuclear/cytosol trafficking of ChREBP. Here, we report $\mathrm{X}$-ray crystal structures of homodimeric mammalian $14-3-3 \beta$ in its apo, Malate-bound forms. The determined apo structure was captured with one monomer in the closed state, whereas the other one had an open conformation. Strikingly, 14-3-3 $\beta$ binds Malate dynamically with a double-closed state, which is distinct from all previously characterized 14-3-3(s) and target ligandbinding modes. Malate docks into a first-time observed cofactor pocket located at the concaved interface of $14-3-3 \beta$ helices $\alpha 2, \alpha 3, \alpha 4$ through mainly electrostatic and hydrogen interactions. Such a Tricarboxylic Acid Cycle intermediate Malate bond model might offer a new approach to further analyze insulin-independent 14-3-3/ChREBP pathway of de novo fat synthesis in the liver.
\end{abstract}

\section{Keywords}

Crystal Structure, 14-3-3 Protein, ChREBP, Transcription Activation, Malate, Malic Acid 


\section{Introduction}

The 14-3-3 proteins are a family of highly conserved and abundant eukaryotic adapter proteins that regulate at least 300 binding partners in vital physiological processes [1], including DNA damage response, transcriptional trafficking, apoptosis, and even neurodegenerative Alzheimer's disease (AD) [2]. 14-3-3(s) form homo- and/or heterodimer that constitute of seven 14-3-3 genes (i.e., $\beta, \gamma$, $\varepsilon, \sigma, \zeta, \tau, \eta)$ in mammals [3] and 15 genes in the plant [4]. All isoforms recognize two phosphorylated-dependent binding motifs with phosphorylation of serine or threnine residues: RSXpSXP (model 1) and RXXXp(S/T)X[PLM] (model 2) [5]. Nevertheless, 14-3-3(s) might also interact with non-phosphorylated peptide, such as ChREBP- $\alpha 2$ helix [6], p190RhoGEF [7], and metabolites, such as AMP generated during fatty acid metabolism [8]. Despite the targets contain phosphorylation modification or not, they all bind to the same amphipathic groove on 14-3-3 [9].

The function of 14-3-3(s) may usually be classified into three distinct modes. The more common one is the induction of conformation change from phosphorylated binding partner imposed mechanically by rigid 14-3-3(s), resulting in the inter-/intra-compartmental sequestration of target protein itself, which supports the "molecular anvil hypothesis" [10]. For instance, the cell-cycle regulator Cdc25B recruits a 14-3-3 monomer which binds to the high-affinity site named "gatekeeper", allowing the other, low-affinity site engaging the second monomer [11]. Changing subcellular localization (i.e., nuclear/cytosol trafficking) is anther common mode. For example, 14-3-3 $\zeta$ regulates nuclear trafficking of protein phosphatase $1 \alpha(\mathrm{PP} 1 \alpha)$ in human cell [12]. Also 14-3-3(s) can act as a scaffold protein to anchor target proteins to one another [9]. Despite 14-3-3(s) have been implicated in diverse diseases, the direct role of up- or down-regulated 14-3-3(s) function in human diseases is not well known yet. Examples are as follows: ( $\mathrm{i}$ 14-3-3 $\sigma$ has been implicated in $\mathrm{AD}$ and breast cancer [13] [14] [15]; (ii 14-3-3 ל/ $\sigma$ has been implicated in Parkinson's disease [16]; (iii 14-3-3 $\gamma$ in the cerebrospinal fluid (CSF) could be used as a marker for patient with Creutzfeldt-Jakob disease [17] and so on.

14-3-3 $\beta$ interacts directly with Ser ${ }^{196}$-phosphorylated ChREBP (inactive), an insulin-independent transcription factor, with high affinity to stabilize ChREBP under low circulating blood glucose and high glucagon level, resulting ChREBP retained cytosolically or exported out of the nucleus [18]. As the glucose level rises (e.g. taking a meal), the ChREBP was dephosphorylated by a specific protein phosphatase (PP2A-AB $\delta$ ), which leads to dissociation of 14-3-3 $\beta$, followed by nuclear localization by binding to importins, and transcriptional activation of glycolytic enzymes and all of the lipogenic enzymes. Hence 14-3-3 $\beta$ function as an "on/off" switch to control the nucler/cytoplastic trafficking of ChREBP. This pathway could origin back to increased concentration of the pentose shunt intermediate xylulose 5-P (Xu5P) [19]. In addition, a new metabolite, identified as AMP, was recently reported to specifically target the interaction between 
ChREBP and 14-3-3 $\beta$ [8]. Together with ketone bodies, AMP therefore inhibits lipogenesis by restricting localization of ChREBP to the cytoplasm. However, the structural details of the mechanism for glucose metabolites regulation are not clear. Yet, to our knowledge, no other metabolite intermediate from Glycolysis was reported to bind 14-3-3 $\beta$ in biochemistry or structure biology to date.

Here we reported the crystal structures of mammalian 14-3-3 $\beta$ protein in its apo and a Tricarboxylic Acid Cycle intermediate Malte bound form. The binding site of Malte is located in a non-canonical binding pocket surround by a complicated electrostatic and hydrogen interface. As a first step in the directly observed structure model of Glycolysis metabolite interaction with $14-3-3 \beta$, the work provides a structural frame for crosstalk of insulin-independent de novo fat synthesis in the liver and energy production in the citric acid cycle through acetyl-CaA formed during oxidation of fatty acids.

\section{Materials and Methods}

\subsection{Protein Cloning, Expression and Purification}

DNA for the full-length mouse 14-3-3 $\beta$ was amplified by polymerase chain reaction (PCR). The PCR genes were cloned into vector pHis-Parallel1 plasmid [20] and expressed in Escherichia coli strain BL21 (DE3) (Novagen) with an $\mathrm{N}$-terminal 6X His tag. Harvested cells were lysed by a pressure homogenizer in a buffer containing $50 \mathrm{mM}$ Tris, $\mathrm{pH} 8.0,300 \mathrm{mM} \mathrm{NaCl}, 20 \mathrm{mM}$ imidazole, $5 \mathrm{mM}$ $\beta$-mercaptoethanol, $1 \mathrm{mM}$ PMSF, and $0.03 \%(\mathrm{v} / \mathrm{v}) \mathrm{Brij}-5$. The clarified cell lysate was incubated with His60 $\mathrm{Ni}$ beads (Clontech) at $4^{\circ} \mathrm{C}$ for one hour, and the bound protein was eluted with liner gradient of 20 - $500 \mathrm{mM}$ imidazole. The pooled fractions were desalted into $50 \mathrm{mM}$ Tris, $\mathrm{pH} 8.0,200 \mathrm{mM} \mathrm{NaCl}, 2 \mathrm{mM}$ DTT. The 6x His tags were removed by TEV protease overnight at room temperature. The cutted 14-3-3 $\beta$ was further purified using a HiTrap Q column (GE Healthcare Life Sciences) followed by Superdex75 gel filtration chromatography (GE Healthcare Life Sciences) and eluted in $50 \mathrm{mM}$ Hepes pH7.5, $100 \mathrm{mM} \mathrm{NaCl}$, and $2 \mathrm{mM}$ DTT. The protein was then concentrated to $61.5 \mathrm{mg} / \mathrm{ml}$, aliquoted, and flash frozen in liquid nitrogen and stored in $-80^{\circ} \mathrm{C}$.

\subsection{Crystallization and Data Collection}

14-3-3 $\beta$ crystals were grown at $20^{\circ} \mathrm{C}$ using the hanging drop vapor diffusion method. For crystallization, $14-3-3 \beta$ was diluted to $44 \mathrm{mg} / \mathrm{ml}$. The reservoir solution for Apo protein (spacegroup P2 $2_{1} 2_{1}$ ) consisted of $2.2 \mathrm{M}$ Sodim Malonate $\mathrm{pH} 7.0$ and was mixed with protein in a 1:1 ratio. For Malate-bound crystal (spacegroup C2), the reservoir solution consisted of 2.1 M DL-Malic acid pH 7.0 and was mixed with protein in a 1:1 ratio. Crystal of Apo protein was transferred to a cryoprotectant solution of $50 \mathrm{mM}$ HEPES pH 7.5, $100 \mathrm{mM}$ $\mathrm{NaCl}, 2 \mathrm{mM}$ DTT, 2.4 M Sodim Malonate and 25\% Glycerol before flash frozen. Crystal of ligand-bound protein was harvested freshly and flash frozen in liquid nitrogen. 


\subsection{Structure Determination and Refinement}

Both crystals were collected at Beamline 19-ID of Advanced Photon Source (APS), Argonne National Laboratory, Lemont, IL. The diffraction images were integrated, merged and scaled using HKL3000 software package [21]. Initial phases were obtained by the molecular replacement method performed using PHENIX Suite [22]. Manual model building was performed using Coot [23]. Further structure refinement was performed using REFMAC5 [24]. The crystal data and final refinement statistics were summarized in Table 1. All figures were drawn using the program PyMOL (The PyMOL Molecular Graphics System, Version 1.7.4 Schrödinger, LLC). The coordinates of 14-3-3 $\beta$ in two forms have been deposited in the Protein Data Bank (Protein Data Bank code) [25].

\section{Result}

\subsection{Structure of Apo 14-3-3 $\beta$}

The overall structural feature of the Apo protein 14-3-3 $\beta$ is W-like homodimer with an aperture existing at the central dimeric interface (Figure 1(a)), similar

(a)

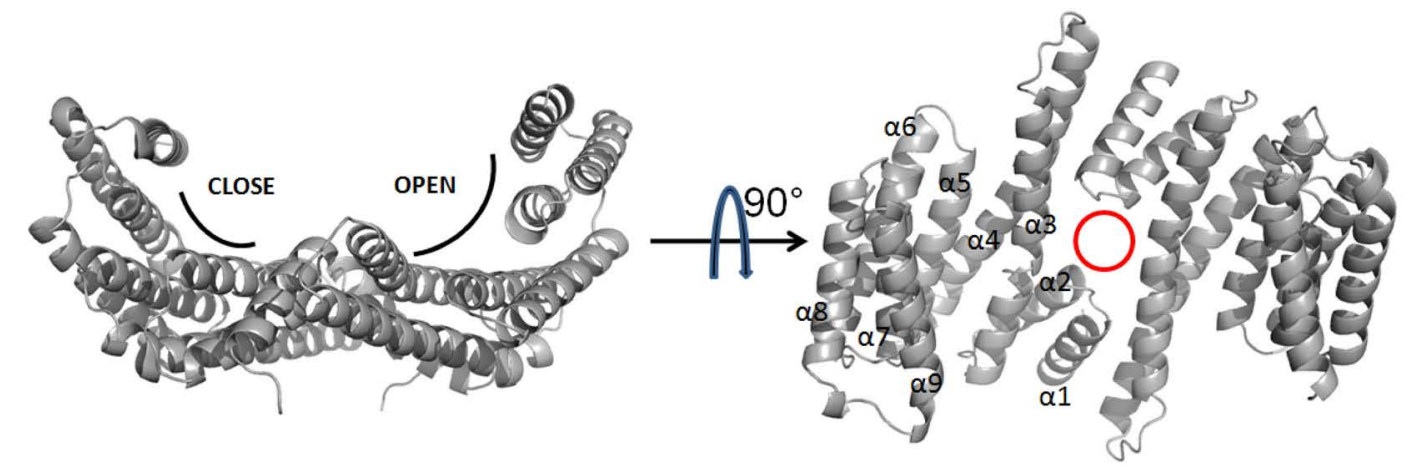

(b)

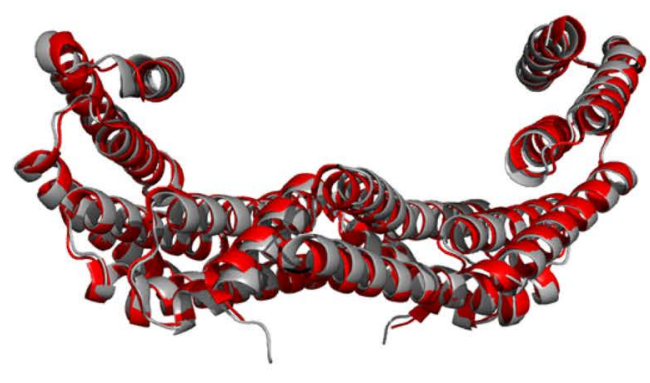

(c)

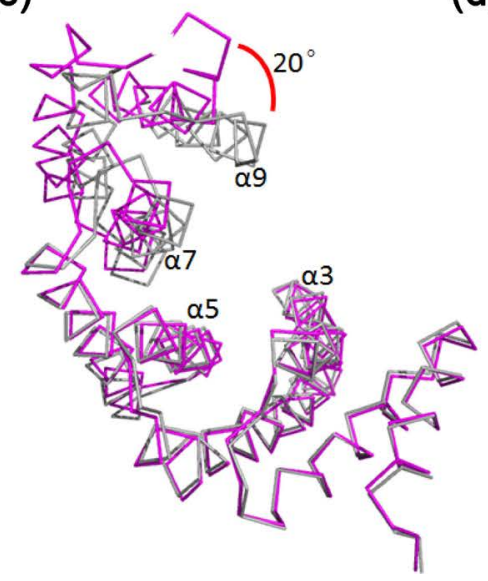

(d)

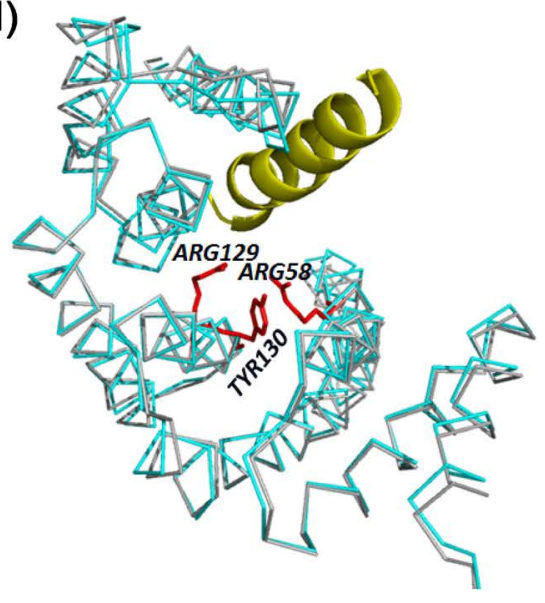

Figure 1. Structure of mouse 14-3-3 $\beta$ in Apo form. (a) Cartoon diagrams of the apo mouse 14-3-3 $\beta$ dimer looking down the canonical peptide binding groove (grey), showing classical "close-open" conformation; (b) The superimposition of m14-3-3 $\beta$ s (2BQ0, red); (c) The superimposition of two monomers in apo 14-3-3 $\beta$ emphasizes the C-terminal flexibility (gray, violet); (d) Close up of positively charged patch in groove that interacts with peptide. 14-3-3 $\beta$ is superimposed to PDB 5F74 (Cyan). Residues are shown as red sticks, peptide from PDB 5F74 is colored yellow. 
to previously reported structures such as PDB ID 2BQ0 (Figure 1(b)). As expected, one monomer was captured in the closed conformation, whereas the opposite one adopts an open state following a $20^{\circ}$ rotation of the $\alpha 7$ to $\alpha 9$ helices, leading to a shallow and exposed groove (Figure 1(a), Figure 1(c)). Each monomer displayed the typical 14-3-3 structural organization, which in general consist of nine helices ( $\alpha 1-\alpha 9)$ arranged in a right-handed superhelical bundle, and organized into groups of two, two, two, and three helice (Figure 1(a)). The first four alpha helices contribute to formation of the dimer, and the subsequent helices always pack in an antiparallel manner. Helices $\alpha 3, \alpha 5, \alpha 7$, and $\alpha 9$ are essential to form the conserved peptide-binding groove located at the concave face of the protein, with dimension about $35 \AA$ (broad) $\times 35 \AA$ (wide) $\times 20 \AA$ (deep) (Figure 1(c)) [26]. One side of the groove contains positively charged patch formed by a conserved triad of Arg-58, Arg-129, Tyr-130 (compare to Arg-57, Arg-130 and Tyr-131 in $\varepsilon$ isoform) that binds to the phosphate group or nonphosphorylated peptide (Figure 1(d)), whilst a hydrophobic patch exist on the other side. Upon superposition, 14-3-3 $\beta$ can be aligned with most homologous structures. For example, structural comparison of the root mean square deviations between $\mathrm{C}^{\alpha}$ atoms of 14-3-3 $\beta$ with peptide-bound structure (PDB ID: 5F74) is only $\sim 0.35 \AA$ with the program CCP4MG [27] (Figure 1(c)). This indicates that ethier apo $14-3-3 \beta$ or complex with peptide adopts essentially identical conformation.

\subsection{Structure of Malate-Bound 14-3-3 $\beta$}

Tricarboxylic Acid Cycle intermediate malate was reported in a shuttle between mitochondrion and cytosol, resulting a far more effective pathway in producing NADPH in the cytosol than the pentose phosphate pathway [28] [29]. We here crystallized $14-3-3 \beta$ together with malate and obtained a $1.97 \AA$ resolution structure (Table 1 ). Striking, 14-3-3 $\beta$ homodimer adopts a double-closed conformation in the malate bound state (Figure $2(\mathrm{a})$ ), suggesting that $14-3-3 \beta$ region encompassing helices $\alpha 7$ and $\alpha 9$ possess a degree of flexibility which contributes to the binding groove changing from an "open" to a "closed" state. Structural comparison of two monomers yields a root mean square deviation of $\sim 0.96 \AA$ for $228 \mathrm{C}^{\alpha}$ atoms (Figure 2(b)), indicating that helices $\alpha 1-\alpha 9$ are largely superimposable. To analyze conformation change on malate binding, we compare the $\mathrm{C}$ terminal helices with other structurally elucidated 14-3-3 canonical closed-open state (PDB ID 2BQ0). Our structure showed that the helices $a 8$ and $\alpha 9$ of monomer A slightly left shift, e.g. $1.9 \AA$ A Leu218 residue on helix $\alpha 9$, but still keeping a closed conformation. However, the C-terminal helical orientation of monomer B displayed significantly flexible difference. The residues, such as Tyr180, Pro187, and Trp230, have been compacted to each other with respect to the superimposed model in open state. The conformational flexibiligty observed here help to explain the mechanism in recognition of diverse peptides with varying size and sequencing by 14-3-3 isoforms. 
Table 1. Data collection and refinement statistics.

\begin{tabular}{|c|c|c|}
\hline & Apo & Malate-bound \\
\hline \multicolumn{3}{|l|}{ Data collection } \\
\hline Space group & $\mathrm{P} 2{ }_{1} 2_{1} 2_{1}$ & $\mathrm{C}_{2}$ \\
\hline \multicolumn{3}{|l|}{ Cell dimensions } \\
\hline$a, b, c(\AA)$ & $59.93,87.79,124.04$ & $265.39,85.60,56.01$ \\
\hline$\alpha, \beta, \gamma\left(^{\circ}\right)$ & $90.00,90.00,90.00$ & $90.00,101.73,90.00$ \\
\hline Resolution $(\AA)$ & $50-1.65(1.68-1.65)^{a}$ & $50.0-1.97(2.00-1.97)^{\mathrm{a}}$ \\
\hline$R_{\text {sym }}$ or $R_{\text {merge }}$ & 0.06 & 0.070 \\
\hline$I / \sigma I$ & $36.3(1.2)$ & $21.9(2.4)$ \\
\hline Completeness (\%) & $99.3(90.2)$ & $99.2(93.2)$ \\
\hline Redundancy & $13.6(7.7)$ & $5.9(4.8)$ \\
\hline Unique reflections & 78578 & 83288 \\
\hline \multicolumn{3}{|l|}{ Refinement } \\
\hline Resolution $(\AA)$ & $50-1.65$ & $50.0-1.97$ \\
\hline No. reflections & 67,495 & 78,469 \\
\hline$R_{\text {work }} / R_{\text {free }}$ & $0.188 / 0.221$ & $0.189 / 0.224$ \\
\hline \multicolumn{3}{|l|}{ No. atoms } \\
\hline Protein & 3681 & 7453 \\
\hline Water & 704 & 376 \\
\hline \multicolumn{3}{|l|}{$B$-factors } \\
\hline Protein & 15.5 & 37.2 \\
\hline Water & 27.9 & 32.4 \\
\hline \multicolumn{3}{|l|}{ R.m.s. deviations } \\
\hline Bond lengths $(\AA)$ & 0.022 & 0.018 \\
\hline Bond angles $\left({ }^{\circ}\right)$ & 1.741 & 1.873 \\
\hline \multicolumn{3}{|l|}{ Ramachandran Plot ${ }^{\mathrm{b}}$} \\
\hline Favored regions (\%) & 100 & 98.6 \\
\hline Outliers (\%) & 0 & 0 \\
\hline
\end{tabular}

${ }^{a}$ Values in parentheses are for the highestresolution shell; ${ }^{\mathrm{b} E v a l u a t e d ~ b y ~ M o l P r o b i t y ~[30] . ~}$

\subsection{The Malate Binding Site}

Generally, the protein 14-3-3 binds to targets through a highly conserved peptidebinding groove with a positively charged patch of Arg-58, Arg-129, Tyr-130 at one side and a hydrophobic patch on the other side (Figure 1(d)). Our malatebound structure revealed an unexpected pocket located in the floor vicinity of 14-3-3 $\beta$ helices $\alpha 2, \alpha 3, \alpha 4$, which distinguishes from the above canonical binding site mainly arranged by helices $\alpha 5, \alpha 7, \alpha 9$ (Figure 3(a)). The observed cavity accommodates the malate perfectly. A close inspection of the interface between 14-3-3 $\beta$ and malate revealed the ligand interacts directly with amino acid resi- 
(a)

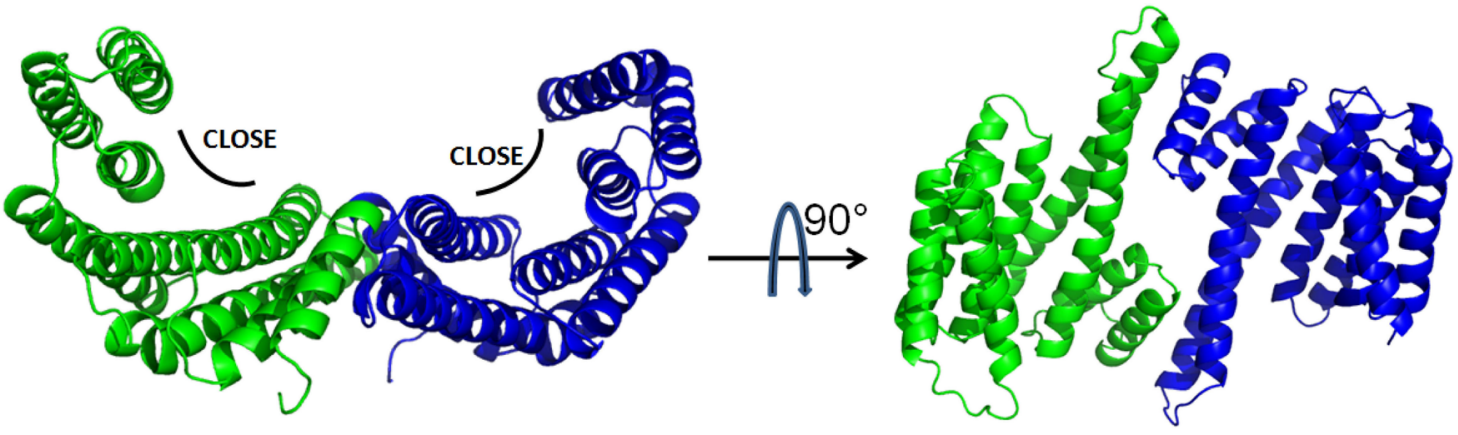

(b)

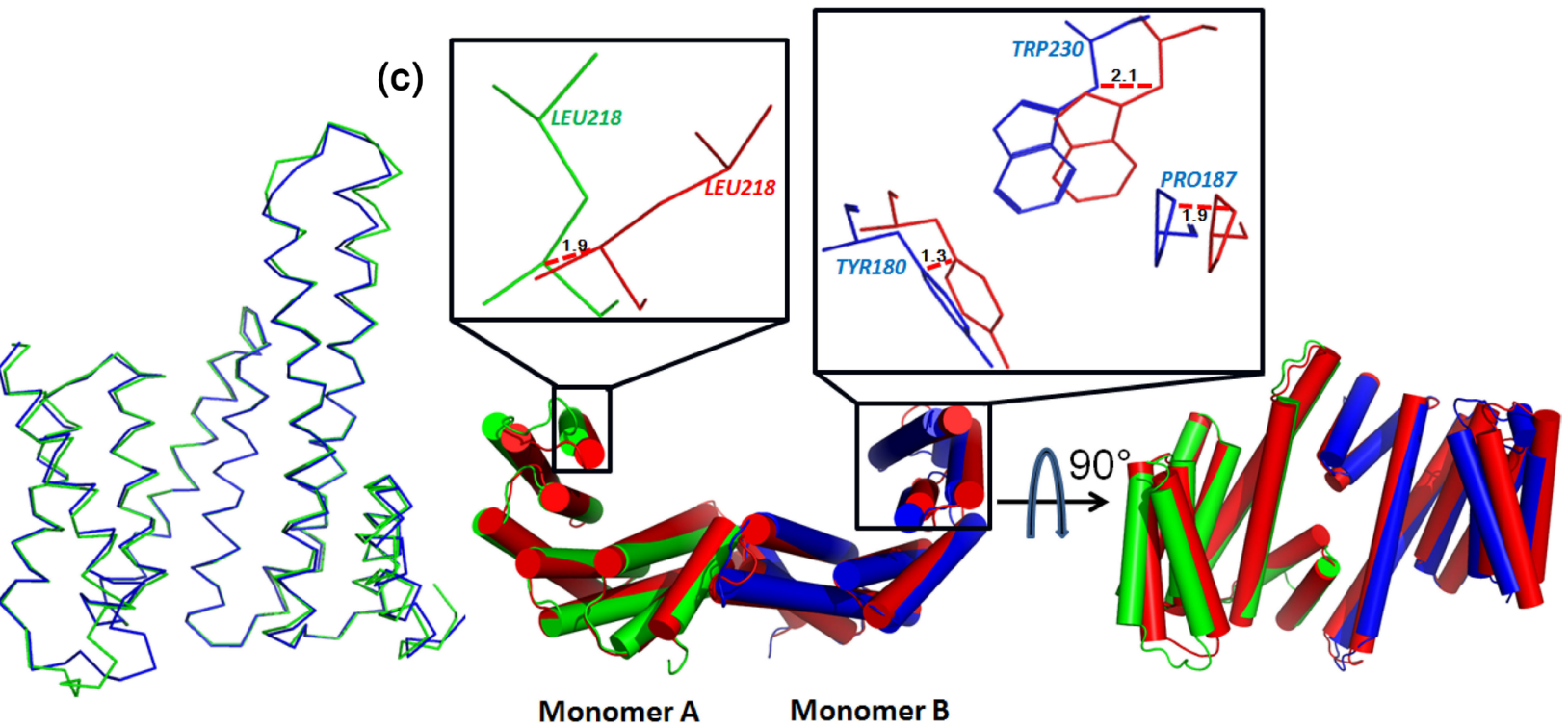

Figure 2. Structure of mouse 14-3-3 $\beta$ in Malate-bound form. (a) Two views of 14-3-3 $\beta$ N-terminal dimer (green, blue); (b) The superimposition of two monomers; (c) Details of residue shift between C-terminal helices. Residues are shown as sticks. The red color model is PDB ID 2BQ0.

dues His36, Leu38 (loop between $\alpha 2$ and $\alpha 3$ ), Try106, Leu107, and Asn110 ( $\alpha 4$ ) through mainly electrostatic and hydrogen interactions. The hydroxyl group on $\mathrm{C}^{1}$ of malate also interacts with Thr32 ( $\left.\alpha 2\right)$ through a water molecule. Two more water forms classical hydrogen bonds with oxygen atoms on $\mathrm{C}^{4}$ of malate (Figure 3(b) and Figure 3(c)) with range $2.7 \AA-2.9 \AA$. The calculated protein-ligand buried interface is $106.9 \AA^{2}$ per monomer.

\section{Discussion and Conclusions}

We determined the crystal structures of the mouse 14-3-3 $\beta$ in Apo and complex with a Tricarboxylic Acid Cycle intermediate malate at $1.65 \AA$ and $1.97 \AA$, respectively. The structure of 14-3-3 in malate-bound form reveals a non canonical binding pocket, located in the floor vicinity of $14-3-3 \beta$ helices $\alpha 2, \alpha 3, \alpha 4$, which was the first time observed in all 14-3-3 family proteins. Intriguingly, malate binding to $14-3-3 \beta$ contributes to the conformation change from "close-open" state in Apo to "close-close" state in complex, raising the possibility that the alteration by malate might regulate the interaction between target proteins like ChREBP with 14-3-3s.

ChREBP is a large transcription factor to activate expression of all the lipogenic 
(a)
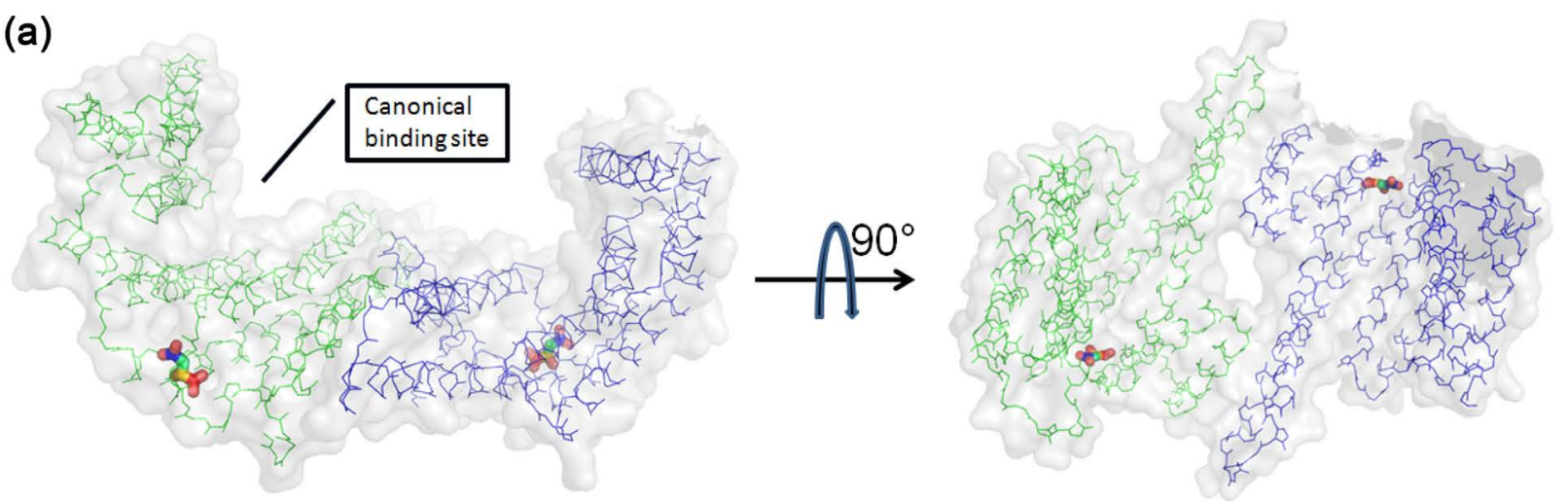

(b)

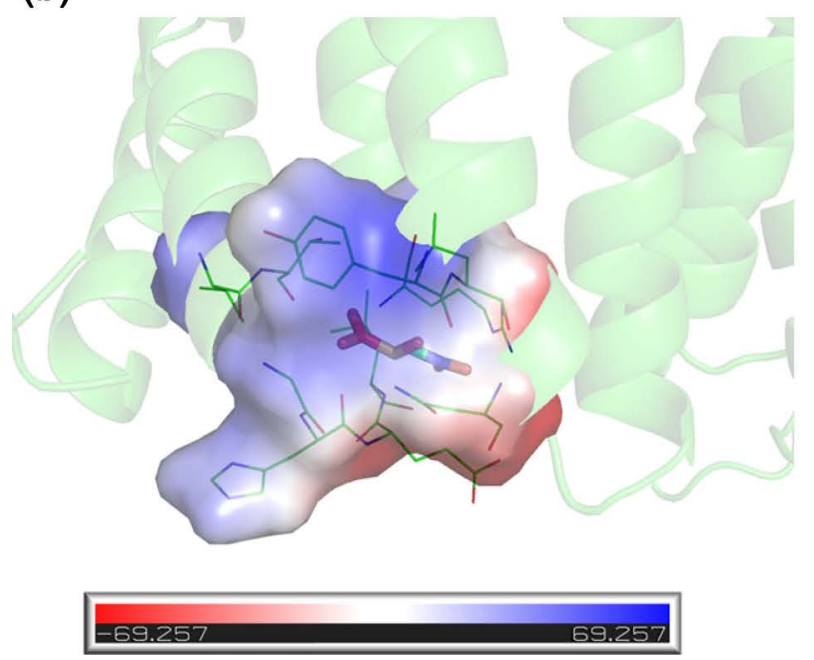

(c)

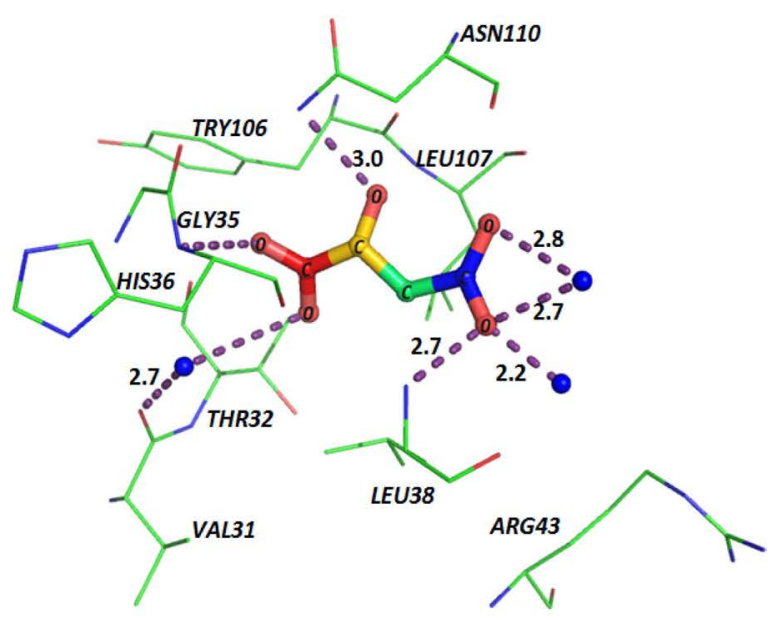

Figure 3. Interaction between non-canonical binding pocket of m14-3-3 $\beta$ with Malate. (a) A ribbon diagram of m14-3-3 dimers with malate shown sticks; (b) Malate binds to a novel groove of 14-3-3 $\beta$ through electrostatic inerations; (c) Detailed view of the malate binding interface. Polar and hydrogen-bond contacts are depicted as purple dotted lines, and residues involved in contacts are shown as sticks. 
Additionally, Glucose 6-phosphate was reported to be required for ChREBP activation in response to glucose in the liver [32]. So far, such interplay between signaling metabolite and ChREBP activation is still not fully understood. Knowledge of the structure interaction mechanism between $14-3-3 \beta$ and metabolites accounting for ChREBP responsiveness to glucose is critical for understating glucose-dependent ChREBP activation. In hence, our Apo- and Tricarboxylic Acid Cycle metabolite malate-bound crystal structures with "on/off" switch function to control the ChREBP trafficking represent the first step toward this goal.

\section{Acknowledgements}

We thank Drs. Diana Tomchick and James Chen for help with synchrotron data collection. Results shown in this report are derived from work performed at Argonne National Laboratory, Structural Biology Center at Advanced Phonton Source. Argonne is operated by UChicago Argonne, LLC, for the U.S. Department of Energy, Office of Biological and Environmental Research under contract DE-AC02-06CH11357.

\section{Accession Numbers}

Atomic coordinates and structure factors for the reported crysal structures have been deposited in the Protein data Bank under accession numbers 5WFU and 5WFX.

\section{Author Contributions}

Z.H. designed experiments and wrote the manuscript, X. L. performed experiments, L. S. analyzed the data.

\section{References}

[1] Bridges, D. and Moorhead, G.B. (2005) 14-3-3 Proteins: A Number of Functions for a Numbered Protein. Science's STKE: Signal Transduction Knowledge Environment, 2005, re10. https://doi.org/10.1126/stke.2962005re10

[2] Joo, Y., Schumacher, B., Landrieu, I., Bartel, M., Smet-Nocca, C., Jang, A., Choi, H.S., Jeon, N.L., Chang, K.A., Kim, H.S., Ottmann, C. and Suh, Y.H. (2015) Involvement of 14-3-3 in Tubulin Instability and Impaired Axon Development Is Mediated by Tau. FASEB Journal: Official Publication of the Federation of American Societies for Experimental Biology, 29, 4133-4144. https://doi.org/10.1096/fj.14-265009

[3] Rosenquist, M., Sehnke, P., Ferl, R.J., Sommarin, M. and Larsson, C. (2000) Evolution of the 14-3-3 Protein Family: Does the Large Number of Isoforms in Multicellular Organisms Reflect Functional Specificity? Journal of Molecular Evolution, 51, 446-458. https://doi.org/10.1007/s002390010107

[4] Siles-Lucas Mdel, M. and Gottstein, B. (2003) The 14-3-3 Protein: A Key Molecule in Parasites as in Other Organisms. Trends in Parasitology, 19, 575-581. https://doi.org/10.1016/j.pt.2003.10.003

[5] Coblitz, B., Wu, M., Shikano, S. and Li, M. (2006) C-Terminal Binding: An Ex- 
panded Repertoire and Function of 14-3-3 Proteins. FEBS Letters, 580, 1531-1535. https://doi.org/10.1016/j.febslet.2006.02.014

[6] Ge, Q., Huang, N., Wynn, R.M., Li, Y., Du, X., Miller, B., Zhang, H. and Uyeda, K. (2012) Structural Characterization of a Unique Interface between Carbohydrate Response Element-Binding Protein (ChREBP) and 14-3-3 $\beta$ Protein. The Journal of Biological Chemistry, 287, 41914-41921. https://doi.org/10.1074/jbc.M112.418855

[7] Zhai, J., Lin, H., Shamim, M., Schlaepfer, W.W. and Canete-Soler, R. (2001) Identification of a Novel Interaction of 14-3-3 with p190RhoGEF. The Journal of Biological Chemistry, 276, 41318-41324. https://doi.org/10.1074/jbc.M107709200

[8] Sato, S., Jung, H., Nakagawa, T., Pawlosky, R., Takeshima, T., Lee, W.R., Sakiyama, H., Laxman, S., Wynn, R.M., Tu, B.P., MacMillan, J.B., De Brabander, J.K., Veech, R.L. and Uyeda, K. (2016) Metabolite Regulation of Nuclear Localization of Carbohydrate-Response Element-binding Protein (ChREBP): Role of Amp as An Allosteric Inhibitor. The Journal of Biological Chemistry, 291, 10515-10527. https://doi.org/10.1074/jbc.M115.708982

[9] Dougherty, M.K. and Morrison, D.K. (2004) Unlocking the Code of 14-3-3. Journal of Cell Science, 117, 1875-1884. https://doi.org/10.1242/jcs.01171

[10] Obsilova, V., Kopecka, M., Kosek, D., Kacirova, M., Kylarova, S., Rezabkova, L. and Obsil, T. (2014) Mechanisms of the 14-3-3 Protein Function: Regulation of Protein Function through Conformational Modulation. Physiological Research, 63, S155S164.

[11] Yaffe, M.B. (2002) How Do 14-3-3 Proteins Work? Gatekeeper Phosphorylation and the Molecular Anvil Hypothesis. FEBS Letters, 513, 53-57.

https://doi.org/10.1016/S0014-5793(01)03288-4

[12] Jerome, M. and Paudel, H.K. (2014) 14-3-3 $\Delta$ Regulates Nuclear Trafficking of Protein Phosphatase 1alpha (PP1 $\alpha$ ) in HEK-293 Cells. Archives of Biochemistry and Biophysics, 558, 28-35. https://doi.org/10.1016/j.abb.2014.06.012

[13] Milroy, L.G., Bartel, M., Henen, M.A., Leysen, S., Adriaans, J.M., Brunsveld, L., Landrieu, I. and Ottmann, C. (2015) Stabilizer-Guided Inhibition of Protein-Protein Interactions. Angewandte Chemie, 54, 15720-15724. https://doi.org/10.1002/anie.201507976

[14] Urano, T., Saito, T., Tsukui, T., Fujita, M., Hosoi, T., Muramatsu, M., Ouchi, Y., and Inoue, S. (2002) Efp Targets 14-3-3 $\sigma$ for Proteolysis and Promotes Breast Tumour Growth. Nature, 417, 871-875. https://doi.org/10.1038/nature00826

[15] Sun, N., Wu, Y., Huang, B., Liu, Q., Dong, Y., Ding, J. and Liu, Y. (2015) Decreased Expression of 14-3-3 $\sigma$, An Early Event of Malignant Transformation of Respiratory Epithelium, Also Facilitates Progression of Squamous Cell Lung Cancer. Thoracic Cancer, 6, 715-721. https://doi.org/10.1111/1759-7714.12246

[16] Dutta, D., Ali, N., Banerjee, E., Singh, R., Naskar, A., Paidi, R.K. and Mohanakumar, K.P. (2017) Low Levels of Prohibitin in Substantia Nigra Makes Dopaminergic Neurons Vulnerable in Parkinson's Disease. Molecular Neurobiology, 54, 1-18.

[17] Wiltfang, J., Otto, M., Baxter, H.C., Bodemer, M., Steinacker, P., Bahn, E., Zerr, I., Kornhuber, J., Kretzschmar, H.A., Poser, S., Ruther, E. and Aitken, A. (1999) Isoform Pattern of 14-3-3 Proteins in the Cerebrospinal Fluid of Patients with Creutzfeldt-Jakob Disease. Journal of Neurochemistry, 73, 2485-2490. https://doi.org/10.1046/j.1471-4159.1999.0732485.x

[18] Sakiyama, H., Wynn, R.M., Lee, W.R., Fukasawa, M., Mizuguchi, H., Gardner, K.H., Repa, J.J. and Uyeda, K. (2008) Regulation of Nuclear Import/Export of Carbohydrate Response Element-Binding Protein (ChREBP): Interaction of an Alpha-Helix 
of ChREBP with the 14-3-3 Proteins and Regulation by Phosphorylation. The Journal of Biological Chemistry, 283, 24899-24908.

https://doi.org/10.1074/jbc.M804308200

[19] Kabashima, T., Kawaguchi, T., Wadzinski, B.E. and Uyeda, K. (2003) Xylulose 5-Phosphate Mediates Glucose-Induced Lipogenesis by Xylulose 5-Phosphate-Activated Protein Phosphatase in Rat Liver. Proceedings of the National Academy of Sciences of the United States of America, 100, 5107-5112.

https://doi.org/10.1073/pnas.0730817100

[20] Sheffield, P., Garrard, S. and Derewenda, Z. (1999) Overcoming Expression and Purification Problems of RhoGDI Using a Family of "Parallel” Expression Vectors. Protein Expression and Purification, 15, 34-39. https://doi.org/10.1006/prep.1998.1003

[21] Otwinowski, Z. and Minor, W. (1997) Processing of X-Ray Diffraction Data Collected in Oscillation Mode. Methods in Enzymology, 276, 307-326. https://doi.org/10.1016/S0076-6879(97)76066-X

[22] Adams, P.D., Afonine, P.V., Bunkoczi, G., Chen, V.B., Davis, I.W., Echols, N., Headd, J.J., Hung, L.W., Kapral, G.J., Grosse-Kunstleve, R.W., McCoy, A.J., Moriarty, N.W., Oeffner, R., Read, R.J., Richardson, D.C., Richardson, J.S., Terwilliger, T.C. and Zwart, P.H. (2010) PHENIX: A Comprehensive Python-Based System for Macromolecular Structure Solution. Acta Crystallographica Section D, Biological Crystallography, 66, 213-221. https://doi.org/10.1107/S0907444909052925

[23] Emsley, P., Lohkamp, B., Scott, W.G. and Cowtan, K. (2010) Features and Development of Coot. Acta Crystallographica Section D, 66, 486-501. https://doi.org/10.1107/S0907444910007493

[24] Bailey, S. (1994) The Ccp4 Suite-Programs for Protein Crystallography. Acta Crystallographica D, 50, 760-763. https://doi.org/10.1107/S0907444994003112

[25] Berman, H.M., Westbrook, J., Feng, Z., Gilliland, G., Bhat, T.N., Weissig, H., Shindyalov, I.N. and Bourne, P.E. (2000) The Protein Data Bank. Nucleic Acids Research, 28, 235-242. https://doi.org/10.1093/nar/28.1.235

[26] Xiao, B., Smerdon, S.J., Jones, D.H., Dodson, G.G., Soneji, Y., Aitken, A. and Gamblin, S.J. (1995) Structure of a 14-3-3 Protein and Implications for Coordination of Multiple Signalling Pathways. Nature, 376, 188-191.

https://doi.org/10.1038/376188a0

[27] Potterton, L., McNicholas, S., Krissinel, E., Gruber, J., Cowtan, K., Emsley, P., Murshudov, G.N., Cohen, S., Perrakis, A. and Noble, M. (2004) Developments in the CCP4 Molecular-Graphics Project. Acta Crystallographica D, 60, 2288-2294. https://doi.org/10.1107/S0907444904023716

[28] MacDonald, M.J. (1995) Feasibility of a Mitochondrial Pyruvate Malate Shuttle in Pancreatic Islets. Further Implication of Cytosolic NADPH in Insulin Secretion. The Journal of Biological Chemistry, 270, 20051-20058.

[29] Ferre, P. and Foufelle, F. (2007) SREBP-1c Transcription Factor and Lipid Homeostasis: Clinical Perspective. Hormone Research, 68, 72-82. https://doi.org/10.1159/000100426

[30] Davis, I.W., Murray, L.W., Richardson, J.S. and Richardson, D.C. (2004) MOLPROBITY: Structure Validation and All-Atom Contact Analysis for Nucleic Acids and Their Complexes. Nucleic Acids Research, 32, W615-W619. https://doi.org/10.1093/nar/gkh398

[31] Nakagawa, T., Ge, Q., Pawlosky, R., Wynn, R.M., Veech, R.L. and Uyeda, K. (2013) Metabolite Regulation of Nucleo-Cytosolic Trafficking of Carbohydrate Response 
Element-Binding Protein (ChREBP): Role of Ketone Bodies. The Journal of Biological Chemistry, 288, 28358-28367. https://doi.org/10.1074/jbc.M113.498550

[32] Dentin, R., Tomas-Cobos, L., Foufelle, F., Leopold, J., Girard, J., Postic, C. and Ferre, P. (2012) Glucose 6-Phosphate, Rather than Xylulose 5-Phosphate, Is Required for the Activation of ChREBP in Response to Glucose in the Liver. Journal of Hepatology, 56, 199-209. https://doi.org/10.1016/j.jhep.2011.07.019

Submit or recommend next manuscript to SCIRP and we will provide best service for you:

Accepting pre-submission inquiries through Email, Facebook, LinkedIn, Twitter, etc. A wide selection of journals (inclusive of 9 subjects, more than 200 journals)

Providing 24-hour high-quality service

User-friendly online submission system

Fair and swift peer-review system

Efficient typesetting and proofreading procedure

Display of the result of downloads and visits, as well as the number of cited articles

Maximum dissemination of your research work

Submit your manuscript at: http://papersubmission.scirp.org/

Or contact jbm@scirp.org 